УСТИНКИН Сергей Васильевич - доктор исторических наук, профессор, декан факультета международных отношений, экономики и управления, профессор кафедры международных отношений и политологии Нижегородского государственного лингвистического университета им. Н.А. Добролюбова (603155, Россия, г. Нижний Новгород, ул. Минина, 31а); директор Приволжсккого филиала ФНИСЦ РАН (603000, Россия, г. Нижний Новгород, пер. Холодный, 4; sv.ustinkin@gmail.com)

КУКОНКОВ Павел Иванович - кандидат социологических наук, старший научный сотрудник Приволжсккого филиала ФНИСЦ РАН (603000, Россия, г. Нижний Новгород, пер. Холодный, 4; kukonkov_pavel@rambler.ru)

МОРОЗОВА Наталья Михайловна - кандидат политических наук, доцент кафедры международных отношений и политологии Нижегородского государственного лингвистического университета им. Н.А. Добролюбова (603155, Россия, г. Нижний Новгород, ул. Минина, 31а); заместитель директора Приволжского филиала ФНИСЦ РАН (603000, Россия, г. Нижний Новгород, пер. Холодный, 4; 4379037@gmail.com)

\title{
РОЛЬ СОЦИАЛЬНЫХ НЕРАВЕНСТВ В ФОРМИРОВАНИИ ОЧАГОВ МЕЖЭТНИЧЕСКОГО НАПРЯЖЕНИЯ
}

Аннотация. В статье авторы показывают, что социальные неравенства во многом определяют природу, функции, динамику межэтнических напряжений и предпринимают попытку проанализировать связи социальных неравенств и межэтнических напряжений в Нижегородской обл. и в других регионах ПФО. Ключевые слова: социальное неравенство, социальное напряжение, межэтническое напряжение, очаг межэтнического напряжения

И сследование социальных напряжений в регионах России существенно затруднено в связи с отсутствием адекватных социологических моделей, отражающих процесс взаимодействия различных социальных субъектов, имеющих не только различные интересы, но и различные темпы их осознания.

Результаты социологических исследований этого явления свидетельствуют, что сложная структура взаимоотношений разных акторов, характеризующихся многомерной идентификацией, определяет социально-идентификационные особенности конкретного региона, но при этом и определяется ими [Дмитриев, Воронов, Михайлова 2017: 98]. На наш взгляд, определение социально-идентификационных особенностей конкретного региона весьма затруднительно. Дело в том, что базой социальных напряжений выступают, прежде всего, различные виды социальных неравенств, генерализация которых в рамках региона практически нереализуема.

В частности, Н.И. Лапин, обращая внимание на повышение человеческого потенциала России, отмечает очень низкий уровень человеческого потенциала примерно в 15 субъектах РФ, где живут $10 \%$ населения страны ${ }^{1}$. Сравнительная оценка межрегионального экономического неравенства внутри 8 федеральных округов, по данным В.Ю. Маслихиной, выявила 3 группы округов со сходным уровнем и динамикой неравенства, причем плотность населения в 4 федеральных округах: Центральном, Приволжском, Северо-Кавказском и Южном

1 Лапин Н.И. Диспропорции между регионами России и социокультурные императивы их развития. Выступление на пленарной сессии Всероссийского социологического конгресса. 21 октября 2008 г. 
составляет 40,5 чел./кв. км, а в 4 остальных округах - только 3,5 чел./кв. км [Маслихина 2017].

Регионы заметно различаются и по уровню безработицы: так, уровень безработицы в Нижегородской обл. ниже, чем в большинстве других регионов России. Ниже он только в Москве, Московской обл., Санкт-Петербурге, Самарской обл., Ямало-Ненецком АО. Самый высокий уровень безработицы в Чеченской, Карачаево-Черкесской республиках, Республике Тыва1.

Заметно варьирует и динамика реальных денежных доходов в РФ, ПФО и Нижегородской обл.: динамика доходов нижегородцев в сторону повышения более заметна по сравнению с ростом доходов населения ПФО и РФ в целом ${ }^{2}$.

Важным показателем, определяющим уровень жизни населения российских регионов, является стоимость и изменение стоимости минимального набора продуктов питания. Так, в марте 2016 г. стоимость минимального набора продуктов питания во всех федеральных округах, кроме Крымского, заметно подросла. В Нижегородской обл. этот показатель стабильно растет более быстрыми темпами, чем в ПФО в целом ${ }^{3}$.

Отмеченные выше различия во многом обусловлены характером развития России, которое в силу совокупности экономических, географических, климатических факторов носило и носит очаговый характер. Очаговый путь развития определяет характер, динамику и направленность процессов, протекающих в основных сферах общества: социальной, экономической, политической, духовной.

Мы считаем вполне обоснованным предположение, в соответствии с которым социальное напряжение также имеет очаговую природу. В «очагах» аккумулируется латентный потенциал социального напряжения, поскольку именно в них формируется специфическая совокупность факторов, влияющих на его возникновение, усиление и трансформацию в социальную активность, социальную пассивность, социальный конфликт, социальную деструкцию. Следовательно, подход, предполагающий изучение социального напряжения в официально установленных границах конкретных территорий, не вполне адекватен, поскольку он не учитывает всю совокупность значимых факторов, характерных для конкретной локально-территориальной общности внутри этой территории и неизбежно элиминируемых при рассмотрении таких образований, как область, край, республика, федеральный округ.

В связи с тем, что характер, динамика и направленность процессов возникновения, усиления и трансформации социальных напряжений тесно связана с масштабами и локализацией их очагов, важной исследовательской задачей выступает определение методов их раннего выявления, описания и анализа их специфики. Эта задача может обрести особую остроту тогда, когда на совокупность проблем, актуальных для большинства российских регионов, накладывается проблема межэтнических отношений. Такая ситуация чаще всего складывается в полиэтнических регионах России. Именно к таким регионам можно отнести ПФО.

Следует подчеркнуть, что более $80 \%$ населения России составляют русские, на долю других национальностей приходится менее $20 \%$. Вместе с тем в отдельных регионах России это соотношение заметно отличается. В частности, в ПФО

\footnotetext{
1 Социальный атлас российских регионов. Независимый институт социальной политики. 2015. Доступ: http://www.socpol.ru/atlas (проверено 14.05.2018).

2 Федеральная служба государственной статистики. Территориальный орган государственной статистики по Нижегородской области. Доступ: http://nizhstat.gks.ru (проверено 14.05.2018).

3 Информация о социально-экономическом положении России: доклад Росстата. Январь-март 2016 г. М.: Росстат.
} 
доля русского населения составляет $68 \%$, доля татар - 13,73\%, армян - 8\%, чувашей $-4,37 \%$, башкир $-4,4 \%$, мордвы $-2,12 \%$, марийцев $-1,62 \%$. Причем в Нижегородской обл., входящей в ПФО, это соотношение отличается как от соотношения по России в целом, так и от соотношения в ПФО: более $95 \%$ здесь составляют русские, а татары, занимающие по этому показателю второе место, $-1,35 \%$ (см. табл. 1$)$.

Таблица 1

\section{Удельный вес лиц данной национальности среди лиц, указавших национальную принадлежность в РФ, ПФО, Нижегородской обл., \%}

\begin{tabular}{|l|c|c|c|}
\hline \multirow{2}{*}{ Национальность } & \multicolumn{3}{|c|}{ Удельный вес лиц данной национальности среди } \\
& \multicolumn{2}{|c|}{ лиц, указавших национальню принадлежность } \\
\cline { 2 - 4 } & РФ$^{1}$ & ПФО $^{2}$ & $\begin{array}{c}\text { Нижегородская } \\
\text { обл. }\end{array}$ \\
\hline Русские & 80,9 & 68,01 & 95,15 \\
\hline Татары & 5,31 & 13,73 & 1,35 \\
\hline Мордва & 0,74 & 2,12 & 0,59 \\
\hline Украинцы & 1,93 & 0,94 & 0,54 \\
\hline Армяне & 1,18 & 8 & 0,41 \\
\hline Чуваши & 1,44 & 4,37 & 0,30 \\
\hline Азербайджанцы & 0,6 & 0,28 & 0,26 \\
\hline Марийцы & 0,55 & 1,62 & 0,20 \\
\hline Белорусы & 0,52 & 0,21 & 0,14 \\
\hline Евреи & 0,11 & 0,07 & 0,12 \\
\hline Узбеки & 0,21 & 0,17 & 0,11 \\
\hline Башкиры & 1,58 & 4,4 & 0,02 \\
\hline
\end{tabular}

1 Результаты переписи населения 2010 года. - Федеральная служба государственной статистики. Доступ: http://www.gks.ru/free_doc/new_site/perepis2010/croc/perepis_itogi1612.htm (проверено 15.05.2018).

2 Национальный состав населения Приволжского федерального округа. 10.09.2013. Доступ: http:// nizhstat.gks.ru (проверено 13.05.2018).

3 Национальный состав населения Нижегородской области. 10.09.2013. Доступ: http://nizhstat.gks. ru (проверено 13.05.2018).

Численность населения ПФО в 2014 г. составила около 29,7 млн чел., или $20,3 \%$ населения России. Округ занимает 2-е место после Центрального по численности населения. Число жителей округа уменьшается. В период между двумя переписями населения (2002-2010 гг.) население сократилось на 1,2 млн чел., или на 4\% (в это же время как население РФ уменьшилось на 1,6\%). Численность населения уменьшилась во всех регионах округа за исключением Республики Татарстан, где был отмечен его рост на $0,2 \%$ за счет превышения миграционного прироста над естественной убылью ${ }^{1 .}$

1 О ходе реализации демографической политики в регионах Приволжского федерального округа: доклад. 29 марта 2013 г. Ижевск. С. 4. РИСИ. Доступ: https://riss.ru (проверено 13.05.2018). 
Обращает на себя внимание то, что по показателю «естественный прирост населения» регионы ПФО также заметно отличаются друг от друга. Так, в январе-марте 2015 г. такой прирост наблюдался только в Республике Татарстан, Астраханской обл. и Удмуртской Республике. В 13 регионах, как и по Российской Федерации в целом, смертность превышала рождаемость. В наибольшей степени это характерно для Пензенской обл. и Республики Мордовия, где численность умерших превысила численность родившихся в 1,7 и 1,6 раза соответственно, а также в Кировской, Нижегородской, Саратовской и Ульяновской обл. - в 1,4 раза 1 .

Весьма примечательно то, что значительные различия наблюдаются также в объемах финансирования государственной национальной политики по отдельным регионам ПФО. В частности, авторы доклада распределенного научного центра межнациональных и межрелигиозных проблем отмечают: «Характерным является распределение субсидий, выделенных в 2015 г. регионам в рамках ФЦП "Укрепление единства российской нации и этнокультурное развитие народов России”. Башкортостану было выделено 33,8 млн руб., Пермскому краю 27,8 млн, Татарстану - 17,9 млн, Удмуртии - 17,4 млн, Самарской области 12,2 млн, Мордовии - 9,4 млн, Марий Эл - 1,9 млн. Саратовской области было выделено только 24 тыс. руб., а Оренбургская область и Чувашия вообще не попали в список регионов, получивших субсидию из федерального бюджета» ${ }^{2}$.

Значительные различия между регионами, которые находят отражение даже в финансировании государственной национальной политики, закономерно сказываются и на различиях внутри них. Следует отметить, что население ощущает эти различия. В частности, треть опрошенных в Нижегородской обл. убеждены, что ситуация в других районах области отличается от ситуации в их районе, причем каждый пятый из них (21\%) считает, что в других городах и районах области ситуация лучше, тогда как $12 \%$ отметили, что там ситуация хуже (см. табл. 2).

Таблица 2

\section{Сравнительная оценка населением ситуации в муниципальном образовании 3}

\begin{tabular}{|l|c|c|c|c|}
\hline $\begin{array}{c}\text { Какова ситуация в других городах и } \\
\text { районах области по сравнению с вашим? }\end{array}$ & $\begin{array}{c}\text { Ниже- } \\
\text { городская } \\
\text { обл. }\end{array}$ & $\begin{array}{c}\text { Нижний } \\
\text { Новгород }\end{array}$ & $\begin{array}{c}\text { Малые и } \\
\text { средние } \\
\text { города }\end{array}$ & $\begin{array}{c}\text { Сельское } \\
\text { население }\end{array}$ \\
\hline Безусловно, хуже & 3,6 & 4,1 & 3,8 & 1,6 \\
\hline Скорее хуже & 13,2 & 13,8 & 15 & 5,6 \\
\hline Не отличается & 40,4 & 36,3 & 38,9 & 56 \\
\hline Скорее лучше & 18,5 & 14,8 & 20,9 & 19,8 \\
\hline Безусловно, лучше & 4,5 & 5,3 & 4,7 & 2 \\
\hline Нет ответа & 19,8 & 25,7 & 16,7 & 15,1 \\
\hline
\end{tabular}

1 Сравнительный анализ основных социально-экономических показателей регионов ПФО, Астраханской и Волгоградской областей со среднероссийскими за январь-март 2015 года. Нижегородстат. Межрегиональные сравнения. Пресс-выпуски. Доступ: http://nizhstat.gks.ru (проверено 13.05.2018).

2 Межэтнические отношения и религиозная ситуация в Приволжском федеральном округе: экспертный доклад 2015 г. (под общ. ред. В.А. Тишкова). М. - Оренбург: ИПК «Университет». 2015. С. 7.

3 Здесь и далее приводятся результаты серии социологических исследований населения Нижегородской обл. в возрасте 18 лет и старше, реализованных Приволжским филиалом ИС РАН в 2011-2017 гг. Выборка случайная, репрезентирующая население по основным социально-демографическим показателям 
Необходимо подчеркнуть, что показатель удовлетворенности жизнью также заметно варьирует в зависимости от района: в частности, неудовлетворенных жизнью сравнительно больше среди населения средних и малых городов Нижегородской обл. $-21 \%$.

Результаты наших исследований свидетельствуют, что сравнительная оценка населением ситуации по месту жительства во многом обусловлена локальнотерриториальным фактором, который обнажает глубину и масштаб неравенств. Нами была выявлена связь между местом проживания и оценкой распространенности основных форм социального неравенства (см. табл. 3).

Наиболее распространенными во всех локально-территориальных общностях являются неравенства в распределении доходов. Обращает на себя внимание, что этот вид социального неравенства сравнительно более распространен в сельской местности, а также в средних и малых городах. Скорее всего, этот факт объясняется большей информированностью жителей о доходах друг друга.

На 2-м месте по степени распространенности находятся неравный доступ к социальным услугам. Особенно ощущается этот вид неравенства жителями сельской местности. Неравенство по национальному (этническому) признаку оказалось на 3-м месте по степени распространенности в Нижнем Новгороде. В сельской местности, а также в средних и малых городах этот вид неравенств ощущается несколько меньше. Здесь на 3-м месте - неравенство жилищных условий.

Таблица 3

\section{Связь между местом проживания и оценкой распространенности основных форм социального неравенства}

\begin{tabular}{|l|c|c|c|}
\hline $\begin{array}{c}\text { Какие из видов социального неравенства, } \\
\text { по Вашему мнению, являются наиболее } \\
\text { распространенными? }\end{array}$ & $\begin{array}{c}\text { Нижний } \\
\text { Новгород }\end{array}$ & $\begin{array}{c}\text { Средние и } \\
\text { малые города }\end{array}$ & $\begin{array}{c}\text { Сельская } \\
\text { местность }\end{array}$ \\
\hline Неравенство в обладании собственностью & 31,2 & 22,3 & 30,5 \\
\hline Неравенство в распределении доходов & 58,7 & 70,7 & 71,2 \\
\hline Неравенство жилищных условий & 34,1 & 37,7 & 40,7 \\
\hline Неравенство между мужчинами и женщинами & 15,8 & 12,7 & 11,0 \\
\hline $\begin{array}{l}\text { Неравенство по национальному (этническому) } \\
\text { признаку }\end{array}$ & 35,5 & 27,0 & 22,0 \\
\hline Неравный доступ к социальным услугам & 42,6 & 42,0 & 50,9 \\
\hline Другое & 0,5 & 0,7 & 1,7 \\
\hline
\end{tabular}

Представленные выше данные свидетельствуют, что зафиксированные в них межрегиональные и внутрирегиональные различия отнюдь не случайны, достаточно стабильны и представляют собой определенную самовоспроизводящуюся систему, формирующую в различных локально-территориальных общностях внутри регионов свою специфическую совокупность факторов социального напряжения. Причем в условиях ПФО велики риски того, что эта совокупность факторов может приобрести выраженную этническую окраску.

По мнению социологов ФНИСЦ РАН, особенность принимающего населения в рамках приволжской региональной модели состоит в том, что оно сформировало поликультурную, но максимально интегрированную на основе рус- 
ских культурных стандартов среду, которую можно обозначить как исторически сложившийся механизм эффективной интеграции инокультурных новаций, что в целом обеспечивает позитивный прогноз развития межэтнических отношений [Дмитриев, Воронов, Михайлова 2017: 114-115]. На основании этого вывода можно сделать наиболее позитивный прогноз развития межэтнических отношений в Нижегородской обл., где поликультурная среда максимально интегрирована на основе русских культурных стандартов. Вместе с тем отсутствуют убедительные данные, подтверждающие этот прогноз.

Мы предполагаем, что в основании потенциальной межэтнической конфликтности лежит рассогласование интересов различных этнических групп в условиях конкретной локально-территориальной общности. Высокие риски негативных сценариев развития межэтнических отношений обусловлены присутствием в рамках конкретной локально-территориальной общности этнических групп, конкурирующих с представителями принимающего сообщества. Усиление такой конкуренции является важным фактором роста межэтнических напряжений и возникновения конфликтов на национальной и религиозной почве (см. табл. 4).

Таблица 4

\section{Распространенность конфликтов на национальной и религиозной почве в Нижегородской обл.}

\begin{tabular}{|c|c|c|c|}
\hline $\begin{array}{c}\text { Были ли вы лично свидетелем конфликтов на } \\
\text { национальной или религиозной почве? }\end{array}$ & $\begin{array}{c}\text { Нижний } \\
\text { Новгород }\end{array}$ & $\begin{array}{c}\text { Средние и } \\
\text { малые города }\end{array}$ & $\begin{array}{r}\text { Сельская } \\
\text { местность } \\
\end{array}$ \\
\hline Да, часто & 9,6 & 8,0 & 5,1 \\
\hline Да, но редко & 23,9 & 22,0 & 16,1 \\
\hline Один-два раза & 26,5 & 21,0 & 17,8 \\
\hline Нет, не был & 34,1 & 43,3 & 55,9 \\
\hline Затрудняюсь ответить & 6,0 & 5,7 & 5,1 \\
\hline
\end{tabular}

Данные, представленные в табл. 4, свидетельствуют, что присутствие этнических групп, конкурирующих с представителями принимающего сообщества в условиях Нижнего Новгорода, чаще ведет к конфликтам на национальной или религиозной почве: две трети нижегородцев (66\%) были свидетелями таких конфликтов. Вместе с тем значительная часть опрошенных в средних и малых городах (43\%) и большинство в сельской местности $(56 \%)$ заявили о том, что не были свидетелями подобных конфликтов.

На наш взгляд, данные, представленные в табл. 4, не являются свидетельством более эффективного процесса формирования интегрированной на основе русских культурных стандартов среды в средних, малых городах и в сельской местности. Скорее всего они представляют собой подтверждение зафиксированного ранее «"кризиса беззащитности", поражающего атомизированные этнические сообщества перед лицом многосторонней экспансии сплоченных этнических кланов» [Андреев 2002: 132]. Мы солидарны с выводом, сделанным авторами упомянутого выше исследования: «Поликультурное и полиэтническое многообразие Российской Федерации обусловливает формирование рисков доминирования отдельных этнических групп на локальных территориях, в отдельных секторах экономической деятельности» [Дмитриев, Воронов, Михайлова 2017: 100].

По данным ВЦИОМа, в последние 10 лет заметно ухудшается отношение к присутствию приезжих других национальностей в таких сферах, как строитель- 
ство и ремонт, продовольственные и вещевые рынки, общественный транспорт, медицина (врачи, медсестры, нянечки), образование (воспитатели, учителя). Причем значительное большинство (72-75\%) плохо относится к их присутствию в таких сферах, как правоохранительные органы и органы местной власти и самоуправления ${ }^{1}$.

Риск обострения межэтнических отношений возрастает по мере нарастания миграционных потоков, объективно изменяющих баланс между этническими и религиозными группами в различных локально-территориальных общностях. В настоящее время Нижегородская обл. имеет положительное сальдо миграции, которое составляет 595 чел. За 2017 г. в область прибыли 33052 чел. и выбыли 32457 чел. Коэффициент миграционного прироста населения Нижегородской обл. за 2017 г. составил 1,8 на 10000 чел. населения ${ }^{2}$. В 2014 г. этот коэффициент по Нижегородской обл. равнялся 5, в РФ - 19, в ПФО $--2^{3}$.

Успешность процессов интеграции и адаптации этнических мигрантов во многом определяется восприятием их массовым сознанием принимающего сообщества (см. табл. 5).

Таблица 5

\section{Распределение представлений о понятии «мигранты» в массовом сознании принимающего сообщества Нижегородской обл. 4}

\begin{tabular}{|l|c|c|c|}
\hline Какой вариант понятия «мигранты» кажется вам & $\begin{array}{c}\text { Нижний } \\
\text { новголее точным? }\end{array}$ & $\begin{array}{c}\text { Средние и } \\
\text { малые города }\end{array}$ & $\begin{array}{c}\text { Сельская } \\
\text { местность }\end{array}$ \\
\hline Все иностранцы & 8,3 & 11,3 & 11,9 \\
\hline $\begin{array}{l}\text { Иностранцы, временно проживающие на } \\
\text { территории России }\end{array}$ & 28,3 & 28,0 & 23,7 \\
\hline $\begin{array}{l}\text { Люди, оказавшиеся в вашем регионе в } \\
\text { результате процессов миграции }\end{array}$ & 31,9 & 29,0 & 22,0 \\
\hline $\begin{array}{l}\text { Все приезжие представители некоренного для } \\
\text { Вашего региона этноса }\end{array}$ & 15,6 & 13,3 & 15,3 \\
\hline $\begin{array}{l}\text { Граждане России, приехавшие в Ваш регион на } \\
\text { заработки }\end{array}$ & 13,6 & 11,0 & 14,4 \\
\hline Затрудняюсь ответить & 2,4 & 6,3 & 12,7 \\
\hline
\end{tabular}

Данные, представленные в табл. 5, свидетельствуют, что в массовом сознании принимающего сообщества Нижегородской обл. отсутствует внятное понимание того, кто может быть отнесен к мигрантам. Непонимание сути явления ведет к отсутствию четкой позиции по отношению к процессу миграции в целом и, как следствие, к повышению рисков реализации негативных сценариев развития отношений между мигрантами и принимающим сообществом, тем более

1 ВЦИОМ. Пресс-выпуск № 3072. 30 марта 2016. года. Доступ: https://wciom.ru (проверено 12.05.2018)

2 Демографическая обстановка в Нижегородской области за январь 2018 года. - Нижегородстат. Пресс-выпуски. Доступ: http://nizhstat.gks.ru (проверено 13.05.2018).

3 Статистика ПФО: статистический сборник № 9. Саранск. - Федеральная служба государственной статистики. 2016. Доступ: http://mrd.gks.ru (проверено 13.05.2018).

4 Здесь и далее приводятся результаты социологического исследования населения Нижегородской обл. в октябре 2017 г. - феврале 2018 г. сотрудниками Приволжского филиала ФНИСЦ РАН. Выборочная совокупность исследования - 970 респондентов. Выборка случайная, репрезентативная по основным социально-демографическим характеристикам. Допустимая погрешность измерения $\pm 3,0 \%$. 
что значительная часть принимающего сообщества ощущает влияние мигрантов на повседневную жизнь поселения (см. табл. 6).

Таблица 6

Оценка влияния присутствия мигрантов на повседневную жизнь поселения

\begin{tabular}{|l|c|c|c|}
\hline $\begin{array}{c}\text { Насколько сильно влияет присутствие мигрантов } \\
\text { в вашем городе (поселении) на вашу жизнь? }\end{array}$ & $\begin{array}{c}\text { Нижний } \\
\text { Новгород }\end{array}$ & $\begin{array}{c}\text { Средние и } \\
\text { малые города }\end{array}$ & $\begin{array}{c}\text { Сельская } \\
\text { местность }\end{array}$ \\
\hline Сильно влияет & 11,1 & 5,7 & 5,1 \\
\hline Влияет незначительно & 31,0 & 28,3 & 21,2 \\
\hline Практически не влияет & 44,4 & 53,3 & 53,4 \\
\hline Никак не влияет & 0,0 & 0,0 & 0,0 \\
\hline Затрудняюсь ответить & 13,6 & 12,7 & 20,3 \\
\hline
\end{tabular}

Данные, представленные в табл. 6, свидетельствуют, что присутствие мигрантов сравнительно более сильно влияет на жизнь населения Нижнего Новгорода и заметно слабее - населения сельской местности. Достаточно очевидно, что такая оценка обусловлена масштабом присутствия мигрантов в той или иной локально-территориальной общности. Именно в таком крупном городе, как Нижний Новгород, изменение баланса этнических групп ведет к усилению конкуренции с представителями принимающего сообщества.

Таблица 7

\section{Связь между местом проживания и отношением к мигрантам и лицам другой национальности}

\begin{tabular}{|c|c|c|c|c|c|c|}
\hline \multirow[b]{2}{*}{$\begin{array}{c}\text { Как вы относитесь к } \\
\text { мигрантам и лицам другой } \\
\text { национальности? }\end{array}$} & \multicolumn{2}{|c|}{ Нижний Новгород } & \multicolumn{2}{|c|}{$\begin{array}{c}\text { Средние и малые } \\
\text { города }\end{array}$} & \multicolumn{2}{|c|}{ Сельская местность } \\
\hline & 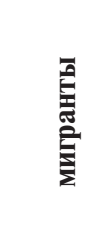 & 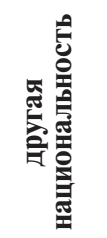 & 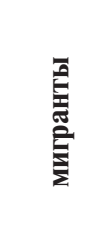 & 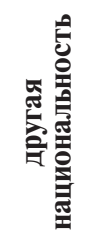 & 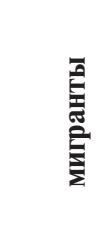 & 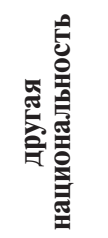 \\
\hline Положительно & 18,5 & 31,0 & 12,0 & 16,0 & 11,9 & 21,2 \\
\hline Нейтрально & 62,9 & 58,5 & 62,0 & 67,7 & 68,6 & 67,8 \\
\hline Отрицательно & 18,7 & 10,5 & 26,0 & 16,3 & 19,5 & 11,0 \\
\hline
\end{tabular}

Данные, представленные в табл. 7, свидетельствуют о заметных различиях в отношении населения к мигрантам и представителям другой национальности, постоянно проживающим в конкретной локально-территориальной общности. Причем отношение к мигрантам более негативное, особенно в средних и малых городах Нижегородской обл.

Анализ данных, полученных в ходе наших исследований, убедительно подтверждает вывод, что измерение межэтнического напряжения в рамках ПФО или в составляющих округ отдельных республиках и областях теоретически не вполне обосновано. Результаты такого измерения не могут репрезентировать уровень социального напряжения в них - слишком велико различие совокупности факторов, определяющих характер, направленность и динамику этого 
явления в различных локально-территориальных общностях. Решение этой задачи возможно только при учете очагового характера межэтнических напряжений. Причем проблема измерения может возникнуть только после решения проблемы выявления и уточнения границ очага межэтнического напряжения.

Признание очаговости социальных напряжений существенно корректирует и функции управления в регионе. И поскольку одной из основных функций государственного и муниципального управления является удержание межэтнического напряжения в рамках, в которых оно не способно оказывать деструктивное влияние на целостность и воспроизводство социальной системы, постольку одной из основных задач выступает выявление очагов межэтнического напряжения, предрасположенных к трансформации в деструктивные социальные конфликты. Учет очагового характера социальных напряжений расширяет возможности их диагностики, предупреждения и локализации, приобретая в настоящее время важное теоретическое и практическое значение.

\section{Список литературы}

Андреев А. 2002. Этническая революция: причины и следствия. - Москва. № 4. C. 126-138.

Дмитриев А.В., Воронов В.В., Михайлова Е.А. 2017. Прогнозное моделирование межэтнических отношений в российских регионах на основе анализа идентификационных стратегий диаспорных и земляческих групп. - Мониторинг общественного мнения. № 6(142). С. 98-125.

Маслихина В.Ю. 2017. Исследование факторов пространственного межрегионального неравенства в России. - Труды Гранберговской конференции: «Пространственный анализ социально-экономических систем: история и современность»: сборник докладов. Новосибирск: ИЭОПП СО РАН.

USTINKIN Sergei Vasil'evich, Dr.Sci (Hist.), Dean of the Faculty of International Relations, Economics and Management; Professor of the Chair of International Relations and Political Science, Dobroljubov State Linguistics University of Nizhny Novgorod (31a Minina St, Nizhny Novgorod, Russia, 603155; sv.ustinkin@gmail.com); Director of Volga branch of the Federal Center of Theoretical and Applied Sociology, Russian Academy of Sciences (4 Holodnyi Lane, Nizhny Novgorod, Russia, 603000)

KUKONKOV Pavel Ivanovich, Cand.Sci. (Soc.), Senior Researcher of Volga branch of the Federal Center for Theoretical and Applied Sociology, Russian Academy of Sciences (4 Holodnyi Lane, Nizhny Novgorod, Russia, 603000; kukonkov_ pavel@rambler.ru)

MOROZOVA Natal'ia Mikhailovna, Cand.Sci. (Pol.Sci), Associate Professor of the Chair of International Relations and Political Science, Dobroljubov State Linguistics University of Nizhny Novgorod (31a Minina St, Nizhny Novgorod, Russia, 603155); Deputy Director of Volga branch of the Federal Center for Theoretical and Applied Sociology, Russian Academy of Sciences (4 Holodnyi Lane, Nizhny Novgorod, Russia, 603000; 4379037@gmail.com)

\section{ROLE OF SOCIAL INEQUALITIES FOR FORMATION OF THE CENTERS OF INTERETHNIC TENSION}

Abstract. The authors show that social inequalities in many respects define the nature, functions, and dynamics of interethnic tension and attempt to analyze communication of social inequalities and interethnic tension in the Nizhny Novgorod Region and in other regions of Volga Federal District.

Keywords: social inequality, social tension, interethnic tension, center of interethnic tension 